\section{La "mala vida" en Buenos Aires. Entre el ensayo criminológico y la literatura marginalizada}

\section{Oscar Conde}

Universidad Pedagógica - Universidad Nacional de las Artes, Argentina

Recibido: 29/12/2017. Aprobado: 28/5/2018.

\begin{abstract}
Resumen
En este trabajo abordaré los dos modos en los que la "mala vida" ha ingresado en la literatura argentina a comienzos del siglo pasado. Por una parte, existen estudios científicos (o pseudocientíficos) acerca de este tema, cuyo arquetipo podría ser $\mathrm{La}$ mala vida en Buenos Aires (1908) de Eusebio Gómez, que contienen muchísimos prejuicios raciales, sociales y sexuales. Por otra, hay un conjunto heterogéneo de textos literarios marginalizados, producidos en los primeros 15 años del siglo XX, que dan cuenta del modus vivendi en los bajos fondos de Buenos Aires, como la novela La muerte del Pibe Oscar de Luis C. Villamayor (publicada parcialmente en 1913 y completa en 1926), el "Novísimo diccionario lunfardo" (1913-1915) del diario Crítica, los folletos de la Biblioteca Criolla, las milongas picarescas, los poemas prostibularios y algunas letras del tango primitivo. Es necesario relacionar este corpus, disperso y muy poco conocido, con el primer conjunto de textos para obtener un panorama más preciso sobre el tema.
\end{abstract}

\section{The "underworld" in Buenos Aires. Between the criminological essay and the marginalized literature}

\footnotetext{
Abstract

This work will focus on the two ways on which the "underworld" has gotten into the Argentinian literature at the beginning of the last century. On the one hand, there are scientific studies (or almost scientific) related to this subject, which archetype could be La mala vida en Buenos Aires (1908) from Eusebio Gómez, that contains a great number of racial, social and sexual prejudices. On the other hand, there is a diverse group of marginalized literature, produced on the first 15 years of the $20^{\text {th }}$ century, that account for the modus vivendi in the underworld of Buenos Aires, like the novel La muerte del Pibe Oscar from Luis C. Villamayor (partially published in 1913 and completed in 1926), the "Novísimo diccionario lunfardo" (1913-1915) from the Critica newspaper, the pamphlets from the Biblioteca Criolla, the cheeky
}

\section{Palabras clave}

mala vida literatura argentina literatura marginalizada tango

\section{Keywords}

underworld Argentinian literature marginalized literature tango 


\section{Palavras-chave}

\section{vida ruim}

literatura argentina

literatura marginalizada tango milongas, the brothel poems and some lyrics from the old tango. It is necessary to connect this corpus, dispersed and little known, with the first group of texts in order to obtain a more precise outlook on the subject.

\section{Resumo}

Neste artigo vou discutir duas maneiras em que a "vida ruim" entrou na literatura Argentina no início do século passado. Por um lado, há estudos científicos (ou pseudo) sobre este assunto, cujo arquétipo poderia ser La mala vida en Buenos Aires (1908) de Eusebio Gómez, que contém muitos preconceitos raciais, sociais e sexuais. Além disso, há um grupo heterogéneo de textos literários marginais produzidos nos primeiros 15 anos do século XX, que representam o modus vivendi nos bairros baixos de Buenos Aires, como o romance La muerte del Pibe Oscar Luis C. Villamayor (parcialmente publicada em 1913 e concluída em 1926), ou "Novísimo diccionario lunfardo" (1913-1915) do jornal Critica, as milongas picarescas, os poemas de bordéis e algumas letras do tango primitivo. É necessário relacionar este corpus, disperso e pouco conhecido, com o primeiro conjunto de textos para obter uma imagem mais precisa do assunto.

En este trabajo abordaré los dos modos en los que la "mala vida" se ha colado en la literatura argentina de comienzos del siglo XX: por un lado, están los que yo englobaría en la categoría de escritos didácticos, es decir, estudios científicos (o pseudocientíficos), recorridos etnográficos, reflexiones desde el púlpito, ensayos sociológicos, psicológicos, sexológicos, antropológicos o filosóficos en torno al tema, cuyo arquetipo bien podría ser el libro La mala vida en Buenos Aires (1908) de Eusebio Gómez. Por otro, recorreré una heterogénea serie de textos más o menos híbridos que dan cuenta del modus vivendi en los bajos fondos porteños, que se revelan para la época como nuevas formas de hacer literatura, pertenecientes casi todos a la categoría de literatura marginalizada desarrollada por Arnaldo Saraiva (1995). Como parte de este segundo conjunto, trataré a continuación un par de ejemplos de la literatura folletinesca la novela La muerte del Pibe Oscar de Luis C. Villamayor, publicada parcialmente en 1913 y completa en 1926, y el "Novísimo diccionario lunfardo", incluido diariamente durante el primer año y medio (1913-1915) del diario Crítica en su página policial-; algunos títulos y textos pertenecientes a folletos (de 8, 16032 páginas) editados profusamente en las ciudades rioplatenses, sobre todo entre 1900 y 1915; unos pocos casos de milongas picarescas o poemas prostibularios, generalmente anónimos; por último, determinados ejemplos del tango cantado, de carácter picaresco, rufianesco o pornográfico, también ubicables en los primeros quince años del siglo pasado.

Según cuenta Roger Chartier (2002), a comienzos del siglo XVI el Consejo de Basilea hizo publicar en Augsburgo el Liber Vagatorum (El libro de los vagabundos), con el objeto de catalogar a los mendicantes. Allí se determinaba la existencia de veintiocho tipos distintos de "falsos pobres", y se revelaban además los principales trucos usados por ellos para atraer la atención de sus eventuales benefactores y/o víctimas.

Un siglo más tarde, se publicó en Italia Il vagabondo (1621) de Giacinto de Nobili, ${ }^{1}$ y por esos años Olivier Chéreau dio a conocer en Francia Le Jargon, ou Langage de l'Argot Réformé (La jerga, o Lenguaje reformado de la mendicidad), donde dedicaba varias páginas a la descripción de una típica "Corte de los Milagros", esto es, una asociación de mendigos y marginales, la mayoría de los cuales eran falsos rengos, ciegos y mudos. Se deduce en Chéreau un interés moral, pues su librito se preocupa por distinguir a los pobres "legítimos" de aquellos mendigos ociosos, estafadores, ladrones y tada de un manuscrito lación ada fines del siglo XV titulado (Espejo de los cerr firmado por un tal Teseo Pini.

Ledición de esta obra se ha perdido; la segunda data de 1630. 
vagabundos. Pero al mismo tiempo incluye distintos textos sueltos escritos en jargon, formas paródicas de tipos textuales como ordenanzas reales, escritos judiciales, fórmulas religiosas, diálogos y poemas.

Estas obras editadas entonces en Europa resultan inseparables tanto del debate sobre las formas legítimas de la caridad como de las precauciones que debían tomarse ante este problema. Pero al mismo tiempo tales estudios sobre los mendigos se conectan con una fructífera y exitosa literatura de la marginalidad o la picardía, representada en España por El Lazarillo de Tormes (1554), Guzmán de Alfarache (primera parte: 1599; segunda parte: 1604) de Mateo Alemán -verdadera obra canónica del género-, la antología Romances de germanía de varios autores (1609) de Juan Hidalgo ${ }^{3}$, la cervantina Rinconete y Cortadillo (1614) y La vida del Buscón llamado don Pablos (1626) de Francisco de Quevedo. En Francia, la novelita La vie généreuse des Mercelots, Gueux et Bohémiens (1596, La vida generosa de los picaros, mendigos y bohemios ${ }^{4}$ ), firmada bajo el seudónimo de Pechon de Ruby, cuenta -sobre el modelo del Lazarillo- la iniciación del protagonista como aprendiz en una banda dedicada al robo y la rapiña, y su relación con mercaderes, vagabundos, salteadores de caminos, mendigos y gitanos.

Las numerosas reediciones de todas las obras nombradas revelan el interés que el tema continuó teniendo entre los europeos en los siglos siguientes. En 1838 el Instituto de Francia convocó a un concurso de ensayos sobre "los elementos que componen, en París o en cualquier otra gran ciudad, esa parte de la población que forma una clase peligrosa por sus vicios, su ignorancia y su miseria" (reproducido en Zaffaroni, 2011: 16). ${ }^{5}$ En la misma época ya se hablaba en Francia del argot du milieu -el argot "del ambiente"-y en Italia, del gergo de la malavita. De modo que la locución "clases peligrosas", aunque toda una declaración de principios, fue efímera y a fines del siglo XIX se prefirió adoptar la igualmente condenatoria y difusa expresión "mala vida".

En la última década de dicho siglo y en la primera del XX en las grandes capitales del mundo se desarrolla un género discursivo específico -el ensayo didáctico sobre la delincuencia, abordado generalmente por médicos o abogados-, que no puede considerarse sino en estrecha relación con la difusión de la prescriptiva higienista, la aparición de nuevas técnicas delictivas y las teorías criminológicas de la época.

Una obra precursora es, en este sentido, La mala vita in Roma (1898) de Alfredo Nicéforo y Scipio Sighele, que rápidamente tuvo su calco en La mala vida en Madrid. Estudio psico-sociológico con dibujos y fotograbados del natural (1901) de Constancio Bernaldo de Quirós y José María Llanas Aguilaniedo. Lo cierto es que en ambos países existía ya un interés y hasta una tradición en estos temas. En España, Manuel Gil Maestre había dado a conocer La criminalidad en Barcelona y en las grandes poblaciones (1886) y Los malhechores de Madrid (1889), Manuel Lugilde y Huerta, su Morfología del robo o ladrones de Madrid (1889) y Rafael Salillas, a su vez, había hecho lo propio con sus obras de referencia: El delincuente español. El lenguaje (Estudio filológico, psicológico y sociológico) con dos vocabularios jergales (1896) y El delincuente español. Hampa (Antropología picaresca) (1898). En Italia, además de la vasta producción de Cesare Lombroso, se destacan La mala vita di Palermo (1900) y Storia della prostituzione in Sicilia (1903) de Antonino Cutrera y Mala vita napoletana (1908) de Giulio Caggiano.

A las obras y autores mencionados, en Los grandes misterios de la mala vida en Buenos Aires (1911), el Dr. Carlos L. Looyer (seudónimo de S. Solari) suma otros textos, que cita profusamente, pero de los que no podríamos asegurar su existencia, como Los bajos fondos vieneses de Rudolf Lowy, La cloaca parisina de Jules Driet, La Maffia sportiva en París de L. Tappen y Mauvais Paris de L. Riet. También, siempre según Looyer, otros autores habrían escrito sobre la mala vida en distintas ciudades: Pietro Sanarello, en Milán; Paolo Casaretto, en Génova; Luiggi Tosti, en Turín; Jesús María Almeida, en Lisboa.
3. Juan Hidalgo sería el seudónimo de Cristóbal de Chaves. La antología incluía un Vocabulario por la orden del a.b.c. para declaración de sus términos y lengua, de 1.165 voces, valiosísimo testimonio del habla argótica española de su tiempo. 4. Importa señalar que el término bohemio tenía por entonces en francés dos acepciones principales: 'gitano' y ‘ladrón'. Es muy posterior la aplicación del vocablo a la vida disipada de los artistas. El primer testimonio de ello se encuentra en la novela Les Bohémiens (1790) de Anne-Gédéon Laffitte, autointitulado Marqués de Pelleport, redescubierta hace pocos años por Robert Darnton. Esta obra, muy anterior a Scènes de la vie de Bohème (1848, Escenas de la vida bohemia) de Henri Murger, fue traducida en 2010 al español por Gabriel Hormaechea.

5. El concurso fue ganado por un comisario de la prefectura del Sena, H. A. Frégier, con el libro Des classes dangereuses de la population dans les grandes villes et des moyens de les rendre meilleures (Las clases peligrosas de la población en las grandes ciudades y las formas de hacerlas mejores), publicado en 1840 en Bruselas. 
6. Se trata de "Los beduinos urbanos", del 18 de marzo de 1879 , y "Los caballeros de industria", del 6 de abril del mismo año. Cf. Lugones, (2011 [1879]): 99-112 y Lugones (2011 [1879]): 113-128, respectivamente. Antes, el 6 de julio de 1878 , se había publicado en $L a$ Prensa un suelto sin firma titulado "El dialecto de los ladrones", donde se aludía a este vocabulario, aunque sin darle un nombre específico.
7. El scruchante es el ladrón de casas; el punguista, el que hurta dinero $u$ otros objetos de valor en transportes públicos o en la calle; el cuentero es el estafador, el que le hace a su víctima el llamado "cuento del tío"; el biabista es el ladrón que actúa con violencia.

8. Asimismo, en los años subsiguientes, Cornelio Moyano Gacitúa publicaría La delincuencia argentina ante algunas cifras y teorías (1905); José Ingenieros, Criminología (1913) y Miguel Lancelotti, La criminalidad en Buenos Aires, a margen de la estadística (1914).

9. En 1903 el nombre pasó a ser Archivos de Psiquiatría, Criminología y Ciencias Afines y, a partir de 1913. Revista de Criminología, Psiquiatría y Medicina Legal, ahora bajo la dirección de Helvio Fernández.
En Buenos Aires el interés por la delincuencia había comenzado en el último cuarto del siglo XIX. En 1879 Benigno Baldomero Lugones, escribiente en el Departamento de Policía, había publicado dos largos artículos ${ }^{6}$ en La Nación sobre la actividad de los ladrones -autodenominados "lunfardos"- y la de los estafadores, donde daba cuenta de un léxico que él suponía asociado a la delincuencia y por eso bautizó con el nombre de lunfardo. Además de entretenimiento, "los textos sobre los lunfardos tenían entonces una función pedagógica, enseñaban a manejarse en una ciudad donde las costumbres se renovaban tan rápido como las palabras" (Galeano, 2011: 39). Esta suerte de etnografía del arte de robar (cf. Galeano, 2009: 90-110) proseguiría con la famosa Galería de ladrones de la Capital (1887) de José S. Álvarez, y sus Memorias de un vigilante, editadas una década más tarde, bajo el seudónimo de Fabio Carrizo. De 1896 data un curioso texto anónimo en la misma línea, cuyo título es Los que viven de lo ajeno en Buenos Aires. Sus ardides y prácticas (una excursión por el mundo lunfardo ilustrada con grabados). La función de la obra es, según sus editores, que se una "el entretenimiento a la utilidad" (reproducido en Barcia, 2002: 26). Tiene el formato de un diálogo entre un avezado policía y un periodista, quienes a lo largo de veintitrés capítulos básicamente exponen, en una sucinta tipología lunfarda, el modus operandi de cuatro especies: el scruchante, el punguista, el cuentero y el biabista. ${ }^{7}$

Desde el derecho penal, Luis María Drago con Los hombres de presa (1888) y Antonio Dellepiane con El idioma del delito. Contribución al estudio de la psicología criminal (1894) aportarían sus respectivas visiones acerca de la criminalidad en Buenos Aires, y sobre todo el segundo consagraría enormes esfuerzos al estudio del lunfardo, pues incluía en su libro el primer diccionario de este argot. ${ }^{8}$

Desde comienzos del siglo pasado mucho ha contribuido a la conformación de la representación social de la mala vida la revista Archivos de Criminología, Medicina Legal, Psiquiatria y Ciencias Afines, fundada en 1902 por José Ingenieros -su director hasta 1913- y Francisco de Veyga?. Así lo explica Mariana Dovio:

\footnotetext{
La imagen de la ciudad a la que había que mantener pura y limpia se oponía a ciertos "focos impuros" representados en zonas marginales de la urbe y que encontraban expresión en diversidad de conductas condensadas en los fenómenos del alcoholismo, la mendicidad, la vagancia, la prostitución y la simulación, entre otras. Estas conductas estimadas inmorales se pueden relacionar con la categoría naciente "mala vida", zona intermedia entre el delito y la locura, con la que se designaba a individuos marginados. (Dovio, 2008: 2)
}

Hoy llama la atención la relación, naturalizada por entonces, entre la marginalidad y las enfermedades psiquiátricas. No debe sorprendernos, si sabemos que la mayor parte de las fuentes de información para la mencionada revista médica procedía de las comisarías, del Servicio de Observación de Alienados del Depósito de Contraventores de la Policía de la Capital y del Instituto de Criminología que funcionaba en la Penitenciaría Nacional, así como también de otras prisiones, asilos de menores y legajos judiciales varios. En el discurso de Archivos se consideraban elementos de la mala vida simuladores, prostitutas, vagabundos, delincuentes, homosexuales y travestidos. Al mismo tiempo se pensaba que, como auxiliares del vicio y del delito, jugaban un rol los dueños de cafés, los fabricantes de licores, los proxenetas, los prestamistas, los reducidores, las adivinas y las curanderas. Todos ellos constituían una suerte de ejército, y se repartían por la ciudad de Buenos Aires en los considerados "bajos fondos sociales" (cafés conciertos, academias de baile, cafetines, pensiones y prostíbulos), que no se hallaban siempre en los suburbios de la urbe, sino muy habitualmente en el centro mismo de la ciudad, como el inquietante Paseo de Julio, hoy Av. Leandro N. Alem (cf. Caride Bartrons, 2015). Según 
observa Dovio, el hecho de que vagabundos -esto es, parásitos-, desequilibrados y viciosos hayan sido analizados a partir de una grilla interpretativa médica sujeta al método clínico implicó considerar como focos infecciosos a la vagancia, la simulación y la prostitución dentro del espacio urbano.

Sin ninguna duda, el libro que recogió en buena medida todos estos acercamientos al tema, y que replicaba el formato y el espíritu de los textos europeos ya mencionados fue La mala vida en Buenos Aires $(1908)^{10}$ de Eusebio Gómez que, como señala Eugenio Zaffaroni, "a más de un siglo de distancia parece un manual de moralina trasnochada, plagado de prejuicios clasistas, sexistas y racistas" (Zaffaroni, 2011:9). Así, en el prólogo, se halla una elocuente definición de Ingenieros: "Denomínanse genéricamente «mala vida» todas las manifestaciones aberrantes de la conducta que implican su inadaptación a las condiciones de lucha por la existencia establecidas por la ética social en determinadas circunstancias de tiempo, modo y lugar" (Gómez, 2011 [1908]: 34).

Es bien conocido que la prostitución en el Buenos Aires del 900 había adquirido un nivel de expansión casi único en el mundo, debido principalmente a dos factores: 1) el desequilibrio poblacional entre mujeres y varones -ya que dos tercios de la inmigración europea que llegaba incesantemente en aquel tiempo estaban constituidos por hombres- y 2) la facilidad con la que operaban los tratantes de mujeres -que venían engañadas de Francia o de Polonia para ser rematadas o vendidas- y los rufianes (canfinfleros o cafishios) criollos, que solían explotar a sus propias concubinas. Según informa Liliana Martiello (2005):

El sistema legislativo reglamentarista en la materia fue impuesto el 5 de enero de 1875, en que la primera ordenanza reglamentaria de la prostitución fue sancionada por la Comisión Municipal de Buenos Aires. Desde entonces, con modificaciones de detalle introducidas por ordenanzas posteriores, durante casi sesenta años existió en la ciudad el régimen de la prostitución reglamentada. Mediante la habilitación municipal de lenocinios y la inscripción obligatoria de las prostitutas, forzadas a un control médico periódico, se pretendió circunscribir el ámbito de ejercicio de "la profesión más antigua del mundo" y evitar la difusión de enfermedades venéreas.

En efecto, existieron prostíbulos legales en la capital argentina desde 1875 hasta 1931, cuando "se dispuso restablecer la vigencia de la Ordenanza Municipal del 30 de diciembre de 1925 , que prohibía la prostitución y que no había tenido vigencia efectiva" (Martiello, 2005). Estos establecimientos convivían con los "clandes" y, según una estimación de Andrés Carretero, a finales del siglo XIX funcionaban en la ciudad 6.000 prostíbulos (cf. Varela, 2005: 46). Horacio Salas aporta precisiones topológicas:

Los prostíbulos, ya fueran legales o clandestinos o sus variantes de café de camareras u otros tugurios por el estilo, estaban ubicados [...] en un rectángulo determinado por las calles Cangallo, 25 de Mayo, Viamonte y Junín, y había clubes clandestinos en Avenida de Mayo, en Flores y en Belgrano. Pero la zona más nutrida quedaba en Libertad, desde Cangallo a Tucumán, donde la casi totalidad de las casas estaban ocupadas por prostíbulos, y luego en la zona de Junín y Lavalle, también los hubo por la Boca y por Combate de los Pozos y Pavón, hasta la calle Rincón. (Salas, 1996: 269)

Así las cosas, ni hace falta decir que la prostitución y la explotación femeninas estaban profundamente naturalizadas en la sociedad argentina ${ }^{11}$. En dicho contexto, además de los quecos o quilombos de distintas categorías y precios, existían las academias de baile y los cafés de camareras con orquestas de señoritas, compuestas mayoritariamente por prostitutas que fingían tocar sus instrumentos, mientras, como en una vidriera, eran elegidas por los clientes y reemplazadas ipso facto por otra chica. Claramente en estos sitios ninguna camarera era solamente camarera y la mayoría
10. Luego de la obra de Gómez se publicaron en la misma línea: en Buenos Aires, la ya mencionada Los grandes misterios de la mala vida en Buenos Aires comparada con la de las grandes capitales europeas de Carlos F. Looyer (1911) -texto asistemático, carente de marco teórico, basado en fuentes periodísticas y en libros o folletos inhallables (¿o inexistentes?) publicados en Europa-y, en Barcelona, La mala vida en Barcelona, anormalidad, miseria y delito (1912) de Max Bembo. También en 1912 se editó en Buenos Aires el drama La mala vida de Vicente Salaverri, que había sido representado con éxito primero en Montevideo y luego en la capital argentina.
11. Cf. Ben (2013). En este artículo muy documentado el autor demuestra esta naturalización a través de las citas de diversos folletos de la época. 
12. Sittengeschichte des Kinos en alemán.

13. Se cree incluso que El Satario, el corto porno más antiguo conservado, habría sido rodado en la Argentina (cf. Cuarterolo, 2015). de las integrantes de la orquesta no eran músicas (Martiello, 2005). Durante las tardes y noches funcionaban los teatros de variedades: según el barrio y la categoría, los espectáculos iban de las picardías inocentes a los números más subidos de tono, que podían incluir desnudos femeninos.

En ese marco tuvo también su lugar el cine pornográfico. Según consigna Andrea Cuarterolo, en su trabajo "Fantasías de nitrato. El cine pornográfico y erótico en la Argentina de principios del siglo XX", ya en 1926 Konrad Haemmerling, miembro del Instituto para la Ciencia Sexual de Berlín, había escrito en su Historia moral del cine ${ }^{12}$-firmada con el seudónimo de Curt Moreck- que "Buenos Aires fue, en la primera década del siglo XX, el principal centro de producción de films pornográficos a nivel mundial" (Cuarterolo, 2015: 99) ${ }^{13}$. Además de haber existido en Buenos Aires (y también en Rosario) distintos emprendimientos para la filmación de este tipo de películas denominadas de "género libre", había varias salas más o menos encubiertas en el mismísimo Paseo de Julio, a unos cientos de metros de la Plaza de Mayo y la casa de gobierno, así como también en los barrios de Barracas y la Boca. Cuarterolo narra la experiencia de un visitante europeo a uno de estos sitios non sanctos:

[...] en 1909, el novelista y guionista luxemburgués Norbert Jacques, futuro creador del personaje del Dr. Mabuse, arribó a la Argentina durante un viaje por el mundo y aquí tuvo un temprano contacto con el ambiente del cine pornográfico. Jacques relata que una noche, durante una excursión por el peligroso barrio de Barracas, fue abordado por un hombre en un pequeño bote que señalando hacia el agua le gritó "Isla Maciel” y, luego, en un pastiche idiomático le espetó: “¡Niña, deutsch, francés, englishmen, amor, dirty Cinematografo! (sic)". El escritor, intrigado, acompañó al hombre en su bote y, al desembarcar en la otra orilla, se topó con una construcción sin ventanas, iluminada con una enorme lámpara con forma de arco que señalaba la entrada. En el techo plano se veía un enorme cartel que decía "Cinematógrafo para hombres solos". Antes de entrar, dos gendarmes revisaron sus bolsillos en busca de armas y Jacques confesó sentirse en un cuento de detectives. Cuando entró, la proyección ya había comenzado. Se trataba de una gran sala con corredores a los lados y una pantalla que colgaba del cielo raso y proyectaba films eróticos, mientras un grupo de aburridos bribones se perseguían los unos a otros y las mujeres circulaban entre los huéspedes, la mayoría alemanes. Mientras tanto, por la pantalla desfilaban todas las formas de "amar", ocasionalmente interrumpidas por lesbianas, pederastas, escenas masturbatorias, sádicos y masoquistas. (Cuarterolo, 2015: 108)

Casi con seguridad el sitio descripto por Jacques era El Farol Colorado, famosísimo burdel que integraba la red de prostíbulos regenteados por la poderosa asociación de tratantes y rufianes conocida como Zwi Migdal, que operó en Buenos Aires entre 1906 y 1930. El establecimiento contaba con un servicio de botes que cruzaban a los clientes a través del Riachuelo desde la capital (ciudad de Buenos Aires) hasta la Isla Maciel (Avellaneda, provincia de Buenos Aires). Tal como se corrobora en la narración de Cuarterolo, al entrar "como si se tratase de un guardarropas, había que dejar las armas, ya fuesen cuchillos o revólveres" (Salas, 1996: 269). Había allí una pianola de rollo, donde habitualmente sonaban tangos, y a menudo se ofrecía "la actuación de cantores que entonaban coplas picarescas" (Cuarterolo, 2015: 109).

También Manuel Gálvez describe el lugar, aunque lo denomina El Farol Rojo, en su novela Historia del arrabal, publicada en 1922: "Era una mezcla de bar, de salón cinematográfico y de lenocinio. Un largo patio de tierra, un techo de zinc, y cuartos cuadrando el patio". Inmediatamente el texto describe que "en la pared del fondo iba pasando un film de "género libre», una serie de las mayores obscenidades que sea posible concebir" (Gálvez, 1980 [1922]: 46). 
Por su parte, el poeta Enrique Cadícamo incluyó en su libro Viento que llevay trae (1945) un poema titulado precisamente "El Farol Colorado" donde evoca aquella malsana atmósfera y del que reproducimos dos estrofas:

La pianola picaba los rollos de los tangos.

El cine picaresco iba horneando el ambiente.

Y algún cantor hacía conmover de repente

cantando con su viola una historia de fango.

\section{$[\ldots]$}

El pecado, la riña, el vicio, la bebida,

el rencor y la sombra, el abuso y el celo

eran las flores malas que producía el suelo

de esa isla del diablo y de la mala vida. (Cadícamo, 1945: 24)

Volviendo al ensayo de Eusebio Gómez -abogado, no médico-, lo que más lo perturbaba era el parasitarismo, pues los sujetos comprendidos en la órbita de la mala vida están invariablemente en rebeldía contra el orden social. Los capítulos de su libro se consagran a los ladrones, los estafadores, los usureros, la prostitución y sus "empresarios", los homosexuales varones, los mendigos y vagabundos y los "parásitos de la superstición", entre los que incluye a frailes y monjas, adivinas, curanderas y médicos charlatanes, algunos de los cuales hasta poseen título. Evidentemente la inclusión de la homosexualidad se destaca en la lista. Gómez, tras mencionar la polémica acerca de si es congénita o adquirida, concluye: "cualquiera que sea la solución a que se arribe para explicar esta monstruosa aberración, los individuos por ella afectados deben incluirse, necesariamente, en el cuadro de la «mala vida» Su moralidad defectuosa [...] justificaría esa inclusión" (Gómez, 2011 [1908]: 138).

Nada tan explícito, sin embargo, como un artículo que Benigno Lugones había publicado en 1880 en una revista científica titulado "Pródromo a una descripción de la pederastia pasiva" $"$ : un texto en torno al coito anal y las relaciones homoeróticas, donde se califica a la homosexualidad masculina como "un síntoma de alienación mental" (Lugones, 2011 [1880]: 169). Gómez coincide en algo con Lugones: la homosexualidad suele adquirirse principalmente en un colegio o internado, donde los propios mentores o compañeros suelen ser los "corruptores". Volviendo a su libro, buena parte del capítulo sobre los homosexuales se detiene en el fenómeno del travestismo, lo que el autor aprovecha para citar testimonios de dos conocidas travestis de la época: Myosotis y la Bella Otero. ${ }^{15}$

Evidentemente, toda la literatura mencionada hasta ahora-con las únicas excepciones de los dos artículos de Lugones publicados en 1879 en el diario de mayor tiraje de aquel tiempo y de Memorias de un vigilante- pertenecía a un circuito de especialistas, que al mismo tiempo eran aristócratas. Es decir que la mala vida retratada allí -aun cuando en ocasiones se confesaban expediciones a los "bajos fondos" por parte de los autores- era la descripción de un mundo ajeno y realmente poco conocido. ${ }^{16}$

Pero dentro de lo que podría denominarse literatura marginalizada ${ }^{17}$ había un segundo circuito alternativo de consumo en torno a estos temas. La obsesión por conocer las tramas humanas de la marginalidad resultó particularmente fogoneada por la prensa, desde la hoja suelta hasta el diario y desde el folleto hasta la revista ilustrada. Fue allí donde, en contigüidad o hibridación, aparecieron nuevas formas de hacer literatura en relación más o menos directa con el tema de la mala vida.

Por ejemplo, respecto de la homosexualidad, hay una nota de Juan José de Soiza Reilly, publicada en la revista Fray Mocho en 1912, denominada "Buenos Aires
14. La referencia original es: Lugones, Benigno B. "Pródromo a una descripción de la pederastia pasiva", Anales del Círculo Médico Argentino, tomo III, año III; № 1 (1879). Buenos Aires: Imprenta de obras de La Nación, pp. 4-16. Reproducida en Lugones, 2011: 163-170.

15. La autobiografía de la Bella Otero había sido publicada por Francisco de Veyga en 1904, en el № 3 de la revista Archivos. Es importante aclarar que el principal objetivo de estas personas era no tanto reivindicar su homosexualidad, sino vestirse de mujeres para, una vez seducidas sus víctimas, proceder a robarles todo lo que pudiesen. En el № 88 de la revista Sherlock Holmes, del 4 de marzo de 1913 , se publica una crónica cuyo título es “Dos bellezas porteñas en la cárcel. Las quiebras del feminismo", donde se revela que han sido encarcelados "dos aventajados rateros a la alta escuela": Ulpiano o Luis Álvarez o Luis Blanco, alias "Bella Otero" o "María Luisa” y José Rodríguez o González, alias “la Morosini”. La nota incluye fotos de ambos personajes vestidos de mujer.

16. Estas ideas sobre la mala vida-ligadas a las fatalidades del estigma hereditario, a la teoría de la degeneración y a la inmigración no deseada procedente de la Europa meridional-por parte de autores "de buena familia" preexistían en distintas novelas publicadas en los últimos años del siglo XIX, tales como ilnocentes o culpables? (1884) del médico Antonio Argerich, En la sangre (1888) de Eugenio Cambaceres y la saga en cinco tomos denominada Libro extraño, que el también médico Francisco Sicardi publicó entre 1894 y 1902 . Este último fue asimismo colaborador de Archivos de Psiquiatría, Criminología y Ciencias Afines, donde en 1910 publicó el artículo "La vida del delito y la prostitución” (№ 2, pp. 11-21). Sobre la novela naturalista argentina y su condición de "ficción somática" pueden consultarse Gnutzmann (1998) y Nouzeilles (2000).

17. Sobre la historia y vigencia de esta categoría, cf. Cilento, Laura y Oscar Conde. "La categoría de literatura marginalizada. Evocación y provocación de un concepto", en Cilento, Laura y Oscar Conde (eds.) Textualidades alternativas. Casos de literaturas marginalizadas en la Argentina. Buenos Aires, en prensa. 
18. Desde el punto de vista temático, José González Castillo fue un poco más allá que Soiza Reilly: en 1914 estrenó su drama Los invertidos, donde se desnudaba la doble vida de un respetable padre de familia. La obra fue prohibida de inmediato.

19. El general Dellepiane fue Jefe de la Policía de la Capital entre 1909 y 1912. Además fue un ingeniero - considerado el padre argentino de la geodesia- con una destacada actuación docente en la Facultad de Ciencias Exactas y Naturales de la Universidad de Buenos Aires. Su figura es particularmente recordada por haber encabezado en enero de 1919 las fuerzas que, por orden del presidente Yrigoyen, reprimieron a los obreros en huelga de la Casa Vasena e Hijos en las jornadas de la recordada Semana Trágica, y asimismo por su lealtad al propio Yrigoyen durante su segunda presidencia, mandato en el cual Dellepiane se desempeñó como Ministro de Guerra. Cf. Rodríguez, 1981: 184-186. tenebroso" y con un primer subtítulo que reza "Ladrones vestidos de mujer". Según este autor, "existen en Buenos Aires tres mil sujetos que se dedican al robo valiéndose del traje femenino" (de Soiza Reilly, 2006 [1912]: 235). Soiza, como Gómez, se refiere a la Bella Otero y también a su rival artística, la Princesa de Borbón, al igual que a otras travestis conocidos en Buenos Aires. Las crónicas de Soiza constituyen una forma de hacer literatura en la prensa, y no solo por los audaces temas que abordan. Se trata de textos híbridos que mixturan la dramatización, el anecdotario, las alusiones históricas o culturales, la crónica de actualidad y el estudio sociológico. ${ }^{18}$

La recientemente exhumada novela del guardiacárcel Luis C. Villamayor titulada La muerte del Pibe Oscar constituye otro ejemplo de esta literatura de la mala vida, que se probó primero en el circuito del folletín -con sus primeros cinco capítulos aparecidos en la revista Sherlock Holmes, en 1913, hasta que esta dejó de salir-y luego fue publicada completa en 1926 en una edición modesta, cuya tirada, casi completa, se perdió en un infortunado incendio antes de salir de la imprenta. Cuenta la vida de un delincuente, arquetipo del lunfardo porteño. El texto fue concebido con más de un objetivo. La idea de prevención adquiere en la novela de Villamayor dos sentidos complementarios: por una parte, al narrarse detalladamente algunos hurtos y robos llevados a cabo por Oscar y su "barra", se previene al eventual lector de cada uno de los modus operandi de la delincuencia urbana de la época; por otra, existe ya desde el prólogo, escrito por el general Luis J. Dellepiane, ${ }^{19}$ la intención explícita de atacar un problema mayor: la falta de una contención social adecuada para los jóvenes que, desorientados y desatendidos, comienzan a delinquir. Desde esa perspectiva, la delincuencia se construye socialmente y un factor esencial es la insensible indiferencia de las clases más acomodadas. El autor no se priva, además, de criticar a distintos criminólogos, achacándoles su falta de contacto efectivo con el ambiente de la cárcel y la realidad de los reclusos.

Pero, más allá de esta doble intención extraliteraria más o menos confesa, La muerte del Pibe Oscar es una novela vertiginosa que bien puede leerse en correlato con $E l$ juguete rabioso de Arlt, del mismo año, y que narra -más que la muerte- la vida de un lunfa llamado Oscar Gache en la primera década del siglo XX en Buenos Aires. Una vida signada por el hurto de dos quesos de un almacén, que a los 11 años lo llevó al Correccional de Menores por seis meses. Seis meses que, por "mala conducta", se extendieron - con un infierno de maltratos, vejaciones y abandono- a 8 años, cuando el Pibe Oscar salió de allí transformado en un perfecto delincuente. A partir de entonces, se cuenta cómo este temible joven accede al liderazgo y al respeto de sus colegas. Hay persecuciones por terrazas y techos, romance, secuencias de robos, fugas carcelarias, asesinatos, y hasta un duelo a cuchillo en medio de una rutina de tango en una romería de Villa Santa Rita. El escenario de sus aventuras se desplaza desde el centro hasta el Mercado de Abasto, desde la Boca hasta el actual Parque Ameghino, desde el Paseo de Julio hasta el mítico Barrio de las Ranas, adyacente al Depósito de Basuras (conocido por entonces como "La Quema"), donde el Pibe se esconde de la Policía. Villamayor construye a su protagonista, devenido delincuente por no quedarle otra -como les sucede a Fierro y a los "gauchos malos" de Gutiérrez-, en estrecha relación con el imaginario social porteño acerca de la delincuencia, que no excluía del todo una construcción literaria en cierto sentido melodramática y a la vez robinhoodesca. Se narra allí el "hondo bajo fondo" del 900, donde además del crimen hay espacio también para la nobleza, el amor, la compasión y la valentía, valores y sentimientos que seguramente Villamayor encontró entre los presos que le tocó custodiar como guardiacárcel en la Penitenciaría Nacional de la Av. Las Heras, en la cárcel de Caseros y en el Penal de Ushuaia.

Otro texto híbrido y curioso en directa relación con la mala vida es el "Novísimo diccionario lunfardo", publicado diariamente en la página policial de Crítica entre septiembre de 1913 y enero de 1915, aunque nunca recogido en libro, cuyo autor fue -bajo el 
seudónimo de Rubén Fastrás- José Antonio Saldías. ¿En qué medida responde a las características del tipo textual diccionario? Desde lo formal, es un listado de palabras ordenadas alfabéticamente seguidas de definiciones. Pero la lectura de algunas entregas del "Novísimo" basta para percibir los desplazamientos, esto es, la marginalización conciente buscada por el autor respecto del posible paradigma: el único diccionario lunfardo existente hasta ese momento, publicado por Dellepiane en 1894. El texto rompe una regla básica de cualquier lexicón argótico: dentro de las propias definiciones se usan lunfardismos. Pero además es muy habitual la utilización de subjetivemas y modalizadores. Aunque, en su tono general, el "Novísimo" presenta un registro informal con huellas de oralidad en el que priman lo coloquial y lo humorístico, el texto permite un abordaje a muchas costumbres de la época y formas de entender la vida, a la naturalización de la explotación y la violencia ejercidas contra la mujer, a la consideración negativa del inmigrante -con su cuota de racismo, de xenofobia y especialmente de antisemitismo-, a los modos de relacionarse y de actuar de malvivientes, mendigos, marginales y, en general, del populus minutus de Buenos Aires y sus suburbios. En suma, sin dejar de ser del todo un diccionario, y uno valioso -dado que contiene voces y expresiones propias de la época no recogidas por otros lexicones posteriores-, el texto puede leerse entrega a entrega como un fresco extraordinario acerca de los bajos fondos porteños y una caprichosa pero variada galería de sus personajes.

Así, entre los lemas del diccionario, pueden hallarse denominaciones de ciertas prácticas cuchilleras, como por ejemplo:

caligrafía. - f. (fig.) Golpe de faca que consiste en escribir una letra cualquiera con la filosa en el escracho del bacán contendiente o de la mina mistonga. Ha habido cuchillero que firmaba con rúbrica y todo.

Sorprende también el uso de algún vocablo que los hablantes consideran de creación más o menos reciente:

gato. - m. Bacán bastante insignificante, reo a quien le da la chifladura por hacerse el literato y el farabutti. Idiota que las labura de bohemio y eximio, aunque no valga ni medio. Por lo general el gato es un reo envenenado que la protesta siempre y que se cree perseguido. Lo natural es que como no vale ni medio en ninguna parte tenga colada. "Se me ha piantado la rea / y si viera con qué gato". (Clásicos. Del Barretero. L. C.)

La voz gato se usaba aproximadamente con el mismo sentido que hoy, para referirse a una persona de poco o ningún valor, y la cita -hecha de memoria, aparentemente, porque en lugar de "mina" Saldías escribe "rea"- corresponde a un poema de ocho décimas titulado "Día de bronca", que Evaristo Carriego, con el seudónimo de El Barretero, había publicado en la revista L.C. el 26 de septiembre de 1912, un par de semanas antes de morir.

El sustantivo común jacobo es un compendio de los clichés en contra de los judíos y, en especial, en torno a su relación con la usura:

jacobo. - [m.] El primer judío que vino al país se llamaba así. Desde entonces empezó la jetta del lunfardo. El ruso, se casó, caloteó, hizo laburar a la esposa, vendió a la hija, le tiró el carrito a las dos e hizo menega, mucha menega. Entonces puso una casa de compra-venta y un anexo de usura. En "la nigocios" compraba a cinco lo que valía cien, teniendo en cuenta que el que corría a vender estaba ahorcado. Vendía a cincuenta lo que valía cinco y seguía tirándole a la mujer y a la hija. La menega la empacaba. Prestaba quinientos haciéndose firmar por mil en un cortísimo plazo. Y así seguía empacando la menega. Un día se murió Jacobo. Su viuda estaba rica. 
Pero como ya lo tenía en el cuerpo, puso una casa "non sancta" y se casó con otro tipo y tuvieron hijos y estos hijos le[s] tiraron el carrito a las hermanas, y de toda esta monstruosa unión, chanchullo y canallada, han salido todos los rusos, Jacobos, judíos, Salomones, que la pululan en este Buenos Aires, donde tantas víctimas hacen que no pueden gritarla porque están ahorcados. Con la soga al cuello.

En los lemas referidos a los diferentes personajes que se van presentando los artículos del diccionario discurren de un tema al otro, como sucede en las entradas Juana (la Blandita) y Jorito (el lungo):

Juana (la Blandita). - Jala papa dueña de una casa de pensión reservada; hija del catorce veces seguidas famoso manco Ludueña, el que se está comiendo una iglesiada en Husuaia [sic] de 19 años y por una macanita que casi no valdría la pena ocuparse de ella. Resulta que una noche de Carnaval andando medio trúa, se le durmió con 22 puñaladas en la boca del estómago a un botón que, unos días antes, lo había pasao por desacato a mano armada. No ven ustedes? Una venganza que no ofende su dinidá de choma respetado.

Jorito (El lungo). - [m.] Campana de triste memoria. Murió en la cárcel correccional de Montevideo, a la temprana edad de 14 años. Patada y trompada que se perdían en un entrevero de reos y otros caballeros, se las ligaba el Torito [sic, por Jorito], que Dios lo tenga en santa paz. Era una gran cosa este turrón. La mama de El lungo, fue cocinera de don Benito y hacía vida marital con el zurdo Bermúdez, un simpático muchacho de 27 años con el cuerpo tatuado a puñaladas. Bermúdez, - por qué no batirlo- tenía un corazoncito de madre. Una madrugada, volviendo de un baile efectuado en Lanús, completamente hecho, mató de dos tiros a un vendedor de pescados. Al día siguiente, entre lágrimas y suspiros declaró que lo había hecho sin querer "por probar qué tal andaba de puntería": Muchachos como Bermúdez van quedando pocos. Qué lástima.

De particular interés, por su relación con el tema que nos ocupa, agregaremos finalmente el lema referido a la calle más famosa y legendaria de Buenos Aires por la cantidad y la reputación de sus prostíbulos:

JUNÍN (calle). - Importantísimo e inolvidable barrio carancanfinflero de otros tiempos mejores para canflinfleros y ranfiosos dados a la vidurria airada. Fue el sitio predilecto de los nenes matones, para efectuar sus hazañas. Se han hecho más fuertes y canyengues en este delicioso paraje que [a] veces ha hecho mala figura Betinotti improvisando.

Famosa también es esta estrada de la pavurosa porque congregó en un corto perímetro todos los peringundines y bolonquis de Buenos Aires.

En la esquina de Junín y Corrientes supieron parar los muchachos naerpis que la vivían del shofiqueo. A los lunfas también les daba por estacionarse en la misma esquina. Pero a estos esgunfiaos no los llevaba otro objeto que el de cauchar [sic, por canchar] con los tiradores de rocas. El chorizo siempre odió sinceramente al turro o bacán que se dedica a la fémina de la davi. Cosa rara. En cambio, por la jermu bolonquera, el chorro más ruina es capaz de dejarse basurear.

Las bicicletas codiciadas y de agallas feroces que se han conocido en este barrio fueron las que se dedicaron al esparo, lanza, descuido, espiante, shuca, berretina, etc., en connivencia con sus paicos.

En uno de los cuatro cafés ubicados por aquel entonces, en Junín y Corrientes, supo hacer sonar su flautín el jorobao "La Mura", musicante de tangos y de quien ya hemos chamuyao largo y tendido. 
Qué muchacho pasiandero no guarda un grato recuerdo de esta rejunada como importante esquina, por la que han desfilado los chomas más entradores del arrabal?

Raro sería que los payadores y poetas de extramuro no tuviesen sus dos o tres décimas dedicadas a la memoria de esta inmortal esquina. Bueno fuera. Se le ha cantado a Sarmiento, San Martín, Bolívar y otros. Estos payadores son unos cara-rotas:

"Me llaman Pancho / El gran pasiandero / Porque soy recién llegado / De Montevideo / Y tengo mi parada / En Junín y Corrientes / Y paso una vida / Como un gran repelente". ("Clásicos lunfas". Tomo II. Pág. 25).

Tómese la reproducción de estos pocos lemas como un ejemplo del estilo compositivo del "Novísimo", así como también de su contenido, de la Weltanschauung que lo inspiraba y de su valor etnográfico y literario.

En tercer lugar, dentro del material literario relativo a la mala vida en el Buenos Aires del período histórico que nos ocupa, tenemos la folletería agrupada bajo el título Biblioteca Criolla por el antropólogo alemán Robert Lehmann-Nitsche, conservada actualmente en el Instituto Iberoamericano de Berlín, que consta de novecientos cincuenta folletos. ${ }^{20}$ Este material se publicó regularmente en las grandes ciudades del Río de la Plata (Buenos Aires, Rosario, La Plata, Montevideo) entre la última década del siglo XIX y las dos primeras del XX. Generalmente las tiradas rondaban los 5.000 o 10.000 ejemplares y el contenido, en la mayoría de los casos, incluye poemas gauchescos, décimas para recitar o entonar con guitarra y composiciones payadoriles. No obstante, hay una porción del corpus consagrada a las crónicas en verso o prosa sobre hechos históricos o políticos, asesinatos, accidentes, incendios, truculencias y otras catástrofes. Varios de los folletos contienen al final una letra de tango, canción o vals, que a menudo se ha modelado sobre una música conocida. Así pueden encontrarse notas como: "Para ser cantado con la música de «Pobre mi madre querida»" o "Se canta con la música del tango «El Argañaraz»". ${ }^{21}$

Algunos títulos de los folletos con crónicas sangrientas son, por ejemplo, Una mujer que hace matar al marido de 44 puñaladas, El crimen de Venado Tuerto, La tragedia de Salto. Un marido celoso que mata a la mujer, a la suegra y 3 cuñadas, Una niña de 6 años violada por un atorrante, Historia de la familia asesinada por el turco Mauhmud Caisia, El crimen de La Paz. Madre que ahorca a 5 hijos y mata al marido, Los apaches en Buenos Aires de Evaristo Luna, Las grandes huelgas de inquilinos. Los últimos sucesos sangrientos o Los crímenes del convento. Una niña de 7 años violada por un... diablo con sotana.

Para dar una idea del estilo, reproduciremos -ateniéndonos a la grafía, los errores tipográficos, la acentuación y la puntuación originales- un pasaje extraído del folleto Una familia italiana de 10 personas asesinada y degollada; bajo el subtítulo "La niña de 8 meses partida por la mitad" se lee:

Al oir esto la infeliz saltó del lecho y quiso correr fuera del cuarto siendo sujetada por los criminales. En este momento Maria la hija menor 8 meses penetro gateando el cuarto llamando á su madre. Quien sabe que pasó en aquel momento por la mente de Eustaquio Benitez. Todos los malos instintos, toda su sangre debestia humana se despertaron en él, porque tomando á la infeliz criatura de una pierna, alza en alto el brazo derecho armado por el pesado facón y de un tremendo hachazo la partió en dos. La mitad del inocente cuerpecito saltó palpitante hacia el lado en que estaba su madre, la que paralizada por el terror mas grande contemplaba la cobarde hazaña de este bandido.

Volvieron a exigirle que dijera donde estaba la plata, pero era inútil la infeliz habia perdido el habla y la razón. Al ver la inutilidad de sus getiones los criminales enfurecidos acosaron a la pobre loca á puñaladas asestandole más de 41 heridas.
20. Para más datos acerca de la colección, pueden consultarse Lisi y Morales-Saravia (1986) y Prieto (2006 [1988]).

21. Una porción del material cantable de esta folletería fue recogido en Guido, Walter y Clara Rey de Guido (1989). Cancionero Rioplatense (18801925). Caracas: Biblioteca Ayacucho. 
De este modo se narraban los sucesos en toda su crudeza, y es de sospechar que al público le agradaba esta forma de expresión. Pero los folletos no siempre se atenían a esta clase de contenidos. Según se anuncia en una contratapa de la Imprenta y Librería Americana de Longo y Argento, de Rosario, el público podía solicitar los catálogos de las distintas colecciones. El título del Catálogo $\mathrm{N}^{\circ} 5$ era "Libros de lectura picaresca", que incluía títulos como Los amores de un cochero con la mucama María de Gabriel Sigal, El Pedo Universal, con las Recetas del Doctor Matasanos, Salsa Picante o Los amores de un gallego con una napolitana. Igualmente, como dicen García y Chicote:

El público masculino, ávido de diversión picaresca, también encontró en los folletos títulos inscriptos en los inicios de la serie literaria pornográfica. Se puede destacar, entre ellos, Pimienta molida, «Nuevo ramillete de versos alegres para hombres solos. Cuadros vivos de la vida real. Picadillo del género verde y canciones de todos los gustos », un cuadernillo con versos de contenido erótico-escatológico con desnudos femeninos en la tapa, y con pie de imprenta en Madrid. (García y Chicote, 2008: 45)

Cabe agregar una descripción de una de esas imágenes, la de la página 2: es la foto en sepia de una mujer desnuda, de espaldas y en cuclillas, debajo de la cual aparece la siguiente cuarteta: "si uno les toca el pan dulce / ellas miran pero luego / sienten un tremendo fuego / por delante y por detrás".

En ocasiones se combinaba una cosa con la otra y, tras la lectura de la escabrosa narración de un crimen, el lector podía disfrutar de un texto picaresco. Esto es lo que sucede con el folleto anónimo La tragedia de Salto. Un marido celoso que mata a la mujer, a la suegra y 3 cuñadas, que se cierra con la letra del presunto tango "Lechero y cocinera":

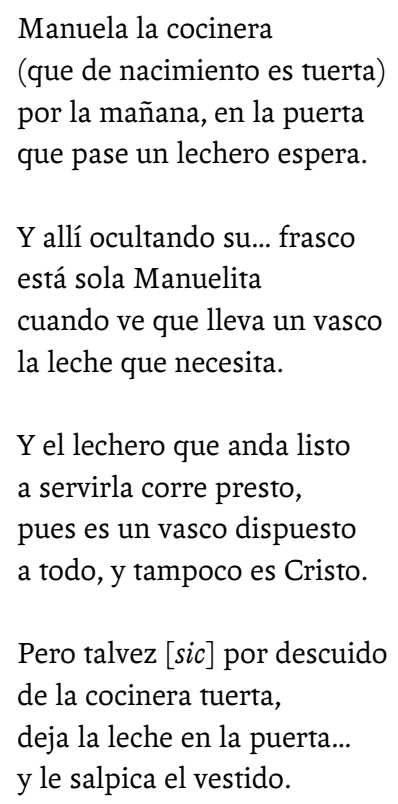

Asimismo, existía en aquel tiempo un vasto corpus de transmisión oral: poesías prostibularias y canciones sicalípticas o, directamente, pornográficas, que se cantaban en varietés y cafés conciertos, en teatros de mala fama y hasta se llegaron a grabar en cilindros de cera o en los legendarios discos de banda verde -no aptos para menores-.

Tan solo como un ejemplo de estas canciones que solían formar parte de los repertorios de las compañías de vodevil, reproduzco un par de estrofas que Lehmann-Nitsche le hizo grabar a José Acevedo en un cilindro en mayo de 1905, y que integra el CD que acompaña el libro Voces de tinta de García y Chicote. Se trata de "Guido en paños", un 
poema humorístico "protagonizado por personajes de la historia y la cultura occidental en situaciones absurdas y socialmente incorrectas" (García y Chicote, 2008: 168). Transcribo aquí las últimas dos estrofas:
Nerón, sentado en dos sillas, vestido de frac y botas, se rascaba las pelotas porque tenía ladillas.
Y sintiendo unas cosquillas más abajo del sobaco, peló del bolsillo un naco para armar un cigarrillo, mientras que Ciro el muy pillo se estaba culiando a Baco.
Carlos Quinto en un rincón estaba medio borracho, peleando con un muchacho por bajarle el pantalón; te conocí la intención, le dijo al punto Aparicio, siempre tuviste ese vicio y agarrando a Pablo Angulo se lo mandó por el culo, rompiéndole el frontispicio.

Como bien señala Gustavo Varela, cuando describe la época:

por entonces Buenos Aires habla de sexo: en las novelas, en los ensayos, en los periódicos anticlericales, en las publicidades gráficas. [...] La gran aldea devenida moderna se expande alrededor de otros conceptos: invertidos, degenerados, masturbación, emoción sexual, coito, instinto, vicio, sodomía, bestialidad. La ciudad arde en miles de prostíbulos y en miles de prostitutas repartidas por sus calles. (Varela, 2014: 65)

Varios de estos textos poéticos, referidos al campo semántico erótico-escatológico -a veces firmados con seudónimo, y casi siempre discretamente anónimos, catalogados por su compilador como Bordellpoesie, esto es, "poesía de burdel"- fueron rescatados por Robert Lehmann-Nitsche tanto en sus Textos eróticos del Río de la Plata (editado originalmente en 1923 en Alemania con el seudónimo de Victor Borde) como en su inédito Folklore argentino, de 1905, publicado recientemente en forma parcial por Miguel García y Gloria Chicote (2008).

El primero es una antología de material más bien obsceno, que incluye poemas lupanarios y excretorios, relaciones, refranes, dichos, cuentos y adivinanzas. Una sección particularmente erótica es la de "poesías épicas", algunos de cuyos títulos hablan a las claras de las epopeyas a las que aluden: "El gran cojedor", "La vida del canfinflero", "Aventuras de una atorranta", "El batallón de putas". Cito parcialmente "Décima del prisionero":

El que es medio bufarrón, ese pasa buena vida, porque toma por querida algún macho bien culón, coje a su satisfacción 
22. Muchos de esos testimonios han sido recogidos en Lamas, Hugo y Enrique Binda (1998). El tango en la sociedad porteña (1880-1920). Buenos Aires: Ediciones Héctor L. Lucci.

\author{
y se queda muy derecho, \\ porque ha sacado el afrecho \\ que tenía allí guardado, \\ pues no lo había sacado \\ después que allí cayó preso. (Lehmann-Nitsche, 1981 [1923]: 74)
}

Corrían por entonces en Buenos Aires letrillas picarescas, rufianescas, prostibularias, que podían cantarse como milongas o recitarse como las relaciones propias de los géneros danzantes del ámbito rural. Están las que comenzaban como una suerte de denuncia con "Señor comisario". Así se escuchaba: "Señor comisario, / deme otro marido, / porque este que tengo / no coge conmigo". A lo que podía responderse: "Señor comisario, / deme otra mujer, / porque esta que tengo / no quiere coger".

Estas cuartetas tenían sus versiones recatadas: "Señor comisario, / deme otro marido, / porque este que tengo / no duerme conmigo". O bien: "porque este que tengo / me ha echado al olvido". Y para el varón: "Señor comisario, / deme otra mujer, / porque esta que tengo / no sabe coser", o también: "Señor comisario, / esa mujer miente, / cuando yo me acuesto / ella no me siente".

Otra letrilla, no sin humor, aludía a la sífilis: "Con tus malas purgaciones / me llenaste un barril / y me tuviste en la cama / febrero, marzo y abril". Sobre la misma temática también se escuchaba: "Por coger con una mina / que era muy dicharachera / me han quedado los cojones / como flor de regadera", que en su versión adecentada resultó: "Por salir con una chica / que era muy dicharachera / me han quedado las orejas / como flor de regadera".

Finalmente, nos detendremos ahora en el tema del tango primitivo y su relación con los tópicos de la mala vida. No existen demasiadas certezas sobre el difuso origen del tango. Sin embargo, todo parece aclararse con el nacimiento del tango-canción, es decir, en el momento en el cual se encuentra una codificación genérica desde el punto de vista literario. Ello sucedió, en primer lugar, merced a la ocurrencia de Pascual Contursi de agregarle letra al tango "Lita" de Samuel Castriota y dar origen así a "Mi noche triste" y, en segundo lugar, gracias a Carlos Gardel, quien grabó este tango en abril de 1917. A medida que se retrocede en el tiempo todo es cada vez más neblinoso e incierto. Más allá de la discusión de si la palabra tango se aplicó primero a la danza o a la música, indudablemente el nombre sirvió en aquellas décadas iniciales para designar ciertas piezas musicales, cantables o no. La creencia generalizada entre los estudiosos acerca del nacimiento del tango, como género musical, en el ámbito prostibulario parece muy difícil de contradecir. Sin embargo, hay diversos testimonios sobre la presencia del tango en otros ambientes populares no necesariamente ligados a la mala vida, como las romerías españolas, las carpas de la Recoleta donde las colectividades de inmigrantes organizaban bailes y espectáculos, los festejos de carnaval y, de modo más cotidiano y modesto, la calle y el patio del conventillo. ${ }^{22}$

No obstante esto, resulta innegable que el tango -en tanto género de linaje y consumo populares- tuvo en sus orígenes una producción en la que muchos títulos jugaban con la doble intención y la picardía criolla no se privaba, en algunos casos, de agregarles a esas músicas versos groseros -ya prostibularios, ya rufianescos- $\mathrm{y}$, en algunos pocos casos, decididamente pornográficos.

Diversos tangos instrumentales - no todos, como se sostiene a veces- tenían, en el origen del género (último cuarto del siglo XIX y primera década del XX), nombres sugestivos, como "Aquí se vacuna" (Juan Lorenzo Labissier), "Manyá qué queso pa' una vidriera..." (Eugenio Tulasne), "Echale leña al fuego” (Julio Belfiore), “¡Cómo me gusta" (Augusto Berto), "Che! Largá ese hueso" (Aleardo Battisti), "Qué rana 
para un charco" (Arturo de Bassi), "Golpeá que te van a abrir" (Ruiz Fernández), "Estate quieto" (Gerardo Metallo) y "Buenos Aires tenebroso" (Adolfo Avilés). Otros llevaban nombres de doble intención, picarescos y hasta impúdicamente obscenos: "La cotorrita" (J. S. Basavilbaso), "La matraca" (Ernesto Cogorno), "La clavada" (Ernesto Zambonini), "El pinchazo" (Ángel Villoldo), "Sacudime la p... ersiana" (Vicente Loduca), "Ladiate" (H. Macchi), "Echale aceite a la manija" (anónimo), "Tocámelo que me gusta" (Prudencio Muñoz), "No, señora... voy torcido" (Pedro Sofía), "Chaucha pelada" (Carlos Minotti), "Echale Bufach al catre"23 (José Manuel Tagle), "Metele bomba al Primus" 24 (José Severino), "Dejalo morir adentro" (José Di Clemente), "Afeitate el 7 que el 8 es fiesta" (Antonio Lagomarsino), "El fierrazo" (Carlos Hernani Macchi), "Haceme un cuatro" (Juan Maglio), "Metele fierro hasta el fondo" (Enrique Saborido), "Hacele el rulo a la vieja" (Ernesto Zóboli), "Tocame «La Carolina»" (Bernardino Terés) y los anónimos "Dos sin sacar" y "Va Celina en punta". Algunos de ellos, de título demasiado explícito, posteriormente fueron adecentados. Así, "La concha de la lora" se convirtió en "La C...ara de la L...una", "iQué polvo con tanto viento!" en "iQué calor con tanto viento!", "Siete pulgadas" -grabado por Carlos Nasca, El Gaucho Relámpago, bajo el título "7 P...as?”- acabó llamándose "Siete palabras" y "Concha sucia" se moralizó como "Cara sucia". La letrilla original de este último decía:

Concha sucia, concha sucia, concha sucia, te has venido con la concha sin lavar, melenuda, melenuda, melenuda, esa concha que tenés sin afeitar.

Que más tarde se cantó así:

$$
\begin{aligned}
& \text { Cara sucia, cara sucia, cara sucia, } \\
& \text { te has venido con la cara sin lavar, } \\
& \text { esa cara tan bonita y picarona } \\
& \text { que refleja una pasión angelical... }
\end{aligned}
$$

En el caso de "La payanca" de Augusto Berto, había una letrilla que rezaba: "Payanca de mi vida, / no te apresures, / que el polvo que te echo / quiero que dure". Más tarde, Juan Andrés Caruso adecentó la letra, partiendo del mismo primer verso: "Payanca de mi vida, / ¡ay!, yo te imploro / que enlaces para siempre / a la que adoro".

Antes de popularizarse la letra de Arturo Mathón, en 1913, a "El Apache Argentino" de Manuel Aróztegui se le había adosado la siguiente letrilla:
Quisiera ser canfinflero
para tener una mina,
metérsela con bencina
y hacerle un hijo aviador,
para que bata el recórd
de la aviación argentina.

A su vez, el tango "Entrada prohibida" de Luis Teisseire llegó a cantarse con los siguientes versos:

$$
\begin{aligned}
& \text { De } L \text { 'Abbaye }{ }^{25} \text { la espiantaron } \\
& \text { y la razón no le dieron, } \\
& \text { pero después le dijeron } \\
& \text { que era por falta de higiene. } \\
& \text { Pues la pobrecita tiene }
\end{aligned}
$$

23. Bufach era una marca de insecticida.

24. Primus era una marca de calentadores de querosén.
25. Es evidente el juego de palabras con Lavalle, nombre de una calle en la que funcionaban muchos burdeles. 
una costumbre asquerosa,

que no se lava la cosa

por no gastar en jabón.

Luego, con letra de Germán Teisseire, "Entrada prohibida" terminó diciendo:

Del cabaret te espiantaron

y te prohibieron la entrada,

se te acabó la parada

te perdiste en el olvido.

$\mathrm{Y}$ un miserable vestido

tuvieron que regalarte,

pues causa pena mirarte

de pobrecita que estás.

También existe, dentro de las letras del tango antiguo, el fenómeno de los contrafacta o contrahechuras, es decir, versos "indecentes" escritos a posteriori de la creación de la letra del tema. Veamos esta estrofa aplicada a "La morocha" de Ángel Villoldo:

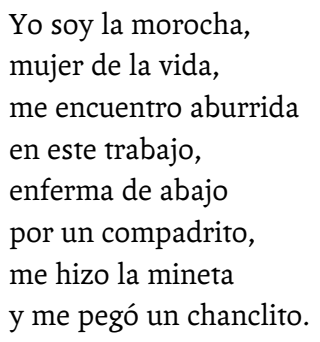

Para concluir con el tango primitivo, es necesario incluir dentro de este panorama, en el que la mayoría de las letras y letrillas son anónimas, precisamente a Villoldo. Dentro de su variadísimo repertorio - preponderantemente, obras propias, que superan las 450 grabaciones- hay una mínima porción de monólogos y diálogos picarescos y canciones sicalípticas, e incluso obscenas, que llegaron a ser grabados o publicados por el artista bajo distintos seudónimos: Fray Pimiento, Lope de la Verga, Juan Techouna, Antonio Techotra, además de otros menos sugerentes, como A. Gregorio, Ángel Arroyo, Gregorio Giménez o Fausto Mendoza.

Algunos ejemplos pueden encontrarse en el valiosísimo libro de Tito Rivadeneira Ángel Villoldo. Su obra en el inicio del tango y de las varietés (2014). Allí se reproducen algunos textos de grabaciones que van a servirnos como ejemplos. Uno de ellos es el diálogo "Los percances de Mario", en el que el protagonista -interpretado por un Villoldo de voz aflautada- le cuenta a un amigo los contratiempos que sufre este joven homosexual molestado permanentemente por distintos admiradores: "-Te han seguido los insolentes. $-¿$ Has visto? Son como las abejas... se vienen a la miel!". Al final, Mario se disculpa con su amigo y se despide con estas palabras: "Adiós, mi querido nene. Me voy porque tengo el corset muy ajustado y me molesta". La intención cómica no excluye el hecho de que no se percibe el más mínimo afán discriminatorio en la conversación entre ambos amigos.

Otro caso es el de las coplas de la composición picaresca "Dómine", en la que se intercala un estribillo cantado, que recuerdan aquellas que comenzaban con "Pican, pican los mosquitos, / pican con gran disimulo", etc.. Reproduzco un par de estrofitas: 
y después de confesarlas, Dómine,

me besaron los coooo...ordones!

$[\cdots]$

Queriendo sacar la grande, Dómine, Juanita compró un billete, Dómine, con terminación en ocho, Dómine,

y le salió por el... siete!

Otros recitados cómicos de este tenor son "Ají picante", "Confesión de un gaucho", "Coplas de Fray Pimiento", "Coplas del Gran Capitán" y "Margarita y su confesor", todos ellos grabados como Fray Pimiento. Villoldo también grabó con el seudónimo de "Un conscripto" la polka "La paraguayita" y "El Tango del siete", dos temas decididamente picarescos. Puede sumarse el poema erótico "La Reja", que Gustavo Varela transcribe en Mal de tango. Elijo una estrofa:

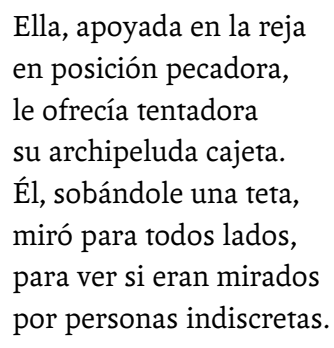

En esta producción deben insertarse ocho tangos que en sus etiquetas no poseen sello, pero fueron grabados para Columbia alrededor de 1910. Estos van más allá que los textos anteriores: son abiertamente procaces. Con el seudónimo de Juan Techouna, Villoldo grabó "El remate de averías", "Historia de Baldomero" y "El banquete del día siete"; con el de Antonio Techotra, los cinco restantes: "Parodia de la Verbena", "Paseo de Julio", "El escándalo de la piedra", "Testamento de Matilde" y "El farrista desgraciado". Infelizmente el celo de los coleccionistas que poseen estas grabaciones no ha permitido aún que se conozca la mayoría de estas letras villoldianas, con excepción de "Paseo de Julio" e "Historia de Baldomero". No obstante, entretanto, me animo a sugerir una pista. Hay una versión de "El testamento de Matilde" en Lehmann-Nitsche (1981 [1923]: 103-104). Quedarían todavía desconocidas las letras de cinco de estos tangos.

El mismo Varela presenta a Villoldo a tono con su tiempo: "lo que los ensayos de criminología exponían de un modo ordenado y con fines científicos Villoldo lo hace carcajada" (Varela, 2014: 66).

La literatura sobre la mala vida ha sido, en las dos vertientes que hemos tratado aquí, profusa y ciertamente difícil de abarcar. Muchísimos de los prejuicios y una gran cantidad de las ideas expuestas en los ensayos didácticos deberían estar, a estas alturas, superados. Pero lamentablemente no es por completo así. Los prejuicios de clase, de raza y de elección sexual perduran en la sociedad argentina de hoy. Respecto del segundo corpus, resulta una literatura hasta ahora dispersa y en gran medida desconocida por los estudiosos, que debe ser puesta en relación con el primer conjunto de textos hasta hacer foco y corregir su miopía o su astigmatismo, según corresponda. 


\section{Bibliografía}

"Barcia, P. L. (2002). “Un olvidado tratado de latrocinio: Los que viven de lo ajeno", en Conde, Oscar y Marcelo Oliveri (comps.). Estudios sobre Tango y Lunfardo ofrecidos a José Gobello. Buenos Aires: Carpe noctem, pp. 25-31.

» Ben, P. (2013). “Historia global y prostitución porteña: El fenómeno de la prostitución moderna en Buenos Aires, 1880-1930", REMS. Revista de Estudios Marítimos y Sociales, Año 5/6, núm. 5/6, noviembre de 2012/2013, pp. 13-26. En línea: <https:// estudiosmaritimos.files.wordpress.com/2014/o1/rems-nc2ba5-6-dossier-gc3agnero-y-clase-ben.pdf> (consulta: 10-10-2017).

»Cadícamo, E. (1945). Viento que lleva y trae. Buenos Aires: Fermata.

»Caride Bartrons, H. (2015). "El infame Paseo de Julio. Imaginarios prostibularios de Buenos Aires”, en Sabugo, Mario (dir.). Metáforas en pugna: estudios sobre los imaginarios del habitar. Buenos Aires: Diseño Editorial, pp. 31-44.

»Chartier, R. (2002). "La construcción estética de la realidad. Vagabundos y pícaros en la Edad Moderna". Tiempos Modernos, Revista electrónica de Historia Moderna, Vol. 3, núm. 7. En línea: <http://www.tiemposmodernos.org/tm3/index.php/tm/article/view/20/39>.

"Cilento, L. y Conde, O. (en prensa). “La categoría de literatura marginalizada. Evocación y provocación de un concepto", en Cilento, Laura y Oscar Conde (eds.). Textualidades alternativas. Casos de literaturas marginalizadas en la Argentina. Buenos Aires: UNIPE Editorial Universitaria.

" Cuarterolo, A. (2015). “Fantasías de nitrato. El cine pornográfico y erótico en la Argentina de principios del siglo XX", Vivomatografías. Revista de estudios sobre precine y cine silente en Latinoamérica, Año 1, núm. 1, diciembre de 2015, pp. 96-125. En línea: <http://www.vivomatografias.com/index.php/vmfs/article/ view/37> (consulta: 08-01-2016).

»De Soiza Reilly, J. J. (2006 [1912]). “Buenos Aires tenebroso”, en La ciudad de los locos. Edición crítica de María Gabriela Mizraje. Buenos Aires: Adriana Hidalgo, pp. 231-246.

"Dovio, M. (2008). "Representaciones sobre la "mala vida" y la criminalidad en Archivos de Psiquiatría, Criminología, Medicina Legal y Ciencias Afines (Buenos Aires, 1902-1913). V Jornadas de Sociología de la UNLP. La Plata: Universidad Nacional de La Plata. En línea: <www.aacademica.com/ooo-096/22/363> (última consulta: 15-9-2017).

» Elías, G. C. (2015). Historias con voz. Buenos Aires: Fundación Industrias Culturales Argentinas.

"Galeano, D. (2009). Escritores, detectives y archivistas. La cultura policial en Buenos Aires, 1821-1910. Buenos Aires: Ediciones Biblioteca Nacional.

» Galeano, D. (2011). "Estudio preliminar. Exhumación de una obra inconclusa", en Lugones, Benigno B. Crónicas, folletines y otros escritos (1879-1884). Buenos Aires: Biblioteca Nacional, pp. 9-96.

» Gálvez, M. (1980 [1922]). Historia de Arrabal. Buenos Aires: Centro Editor de América Latina. 
» García, M. y Chicote, G. (2008). Voces de tinta. Estudio preliminar y antología comentada de Folklore argentino (1905) de Robert Lehmann-Nitsche. La Plata: Universidad Nacional de La Plata.

» Gómez, E. (2011 [1908]). La mala vida en Buenos Aires. Buenos Aires: Biblioteca Nacional.

» Gnutzmann, R. (1998). La novela naturalista en Argentina (1889-1900). Amsterdam: Rodopi.

» Lehmann-Nitsche, R. (1981 [1923]). Textos eróticos del Río de la Plata. Buenos Aires, Librería Clásica [1 ${ }^{a}$ edición: Borde, Victor (1923). Texte aus den La PlataGebieten in volkstümlichem Spanisch und Rotwelsch. Leipzig: Ethnologischer Verlag Dr. Friedrich S. Krauss].

" Lisi, C. y Morales-Saravia, J. (1986). “La «biblioteca criolla» del Fondo LehmannNitsche en el Instituto Ibero-Americano de Berlin", Cahiers du monde hispanique et luso-brésilien, núm.47, pp. 41-49.

»Looyer, C. F. (1911). Los grandes misterios de la mala vida en Buenos Aires comparada con la de las grandes capitales europeas. Cuadros del vicio y del crimen. Obra psico-sociológica por el Dr. Looyer. Ilustrada. Buenos Aires: Talleres Gráficos de Rafael Palumbo.

»Lugones, B. B. (2011). "Pródromo a una descripción de la pederastia pasiva”, en Crónicas, folletines y otros escritos (1879-1884). Buenos Aires: Biblioteca Nacional, pp. 163-170.

»Martiello, L. (2005). “Apuntes para una historia de la prostitución en Buenos Aires (1920-1940)", Persona. Revista electrónica mensual de derechos existenciales, núm. 37. Disponible en <http://www.revistapersona.com.ar/ Persona37/37Martiello.htm> (última consulta: 12-09-2017).

»Nouzeilles, G. (2000). Ficciones somáticas. Naturalismo, nacionalismo y políticas médicas del cuerpo (Argentina 1880-1910). Rosario: Beatriz Viterbo.

»Prieto, A. (2006 [1988]). El discurso criollista en la formación de la Argentina moderna. Buenos Aires: Siglo XXI.

»Rivadeneira, T. (2014). Ángel Villoldo. Su obra en el inicio del tango y de las varietés. Buenos Aires: Dunken.

» s.a. (s.f.). Una familia italiana de 10 personas asesinada y degollada con el Tango “El compadre”. Rosario: Imprenta y Librería Americana.

» s.a. (s.f.). La tragedia de Salto. Un marido celoso que mata a la mujer, a la suegra y $3 \mathrm{cu}$ ñadas con el tango "Lechero y cocinera”. Rosario: Imprenta y Librería Americana.

» s.a. (1913). “Dos bellezas porteñas en la cárcel. Las quiebras del feminismo", Sherlock Holmes, núm. 88, 4 de marzo, s.p.

》Salas, H. (1986). El tango. Buenos Aires: Planeta.

» Salas, H. (1996). El Centenario. Buenos Aires: Planeta.

»Saraiva, A. (1995) “La literatura marginal”, en Anthropos, núm. 166/167, Barcelona, mayo-agosto de 1995, pp. 21-24.

»Selles, R. (2010). El origen del tango. Buenos Aires: Marcelo Oliveri Editor.

"Varela, G. (2014). La Argentina estrábica. Buenos Aires: Ediciones Godot.

»Varela, G. (2004). Mal de tango. Historia y genealogía moral de la música ciudadana. Buenos Aires: Paidós. 
»Villamayor, L. C. (2015 [1926]). La muerte del Pibe Oscar. Estudio preliminar, edición, glosario, apéndices y notas por Oscar Conde. Buenos Aires: UNIPE Editorial Universitaria.

»Zaffaroni, E. (2011 [1908]). “Estudio preliminar”, en Gómez, E., La mala vida en Buenos Aires. Buenos Aires: Ediciones Biblioteca Nacional, pp. 9-28. 